\title{
ALGUNAS CONSIDERACIONES CLINICAS GENERALES SOBRE POLIOMIELITIS
}

\author{
Par los Dres. ADALBERTO STEEgER. CELSO SANTIBAÑEZ y ARIEL RAMOS \\ Hospital Masuel Arriarán. Clínica Extraordinaria de Pediatria del Prof. A. Steeger.
}

Durante el período comprendido entre los años 1948 y 1951 hemos tenido oportunidad de atender en los Servicios del Hospital Arriarán un total de 220 casos de poliomielitis, manifestada en sus diversas formas clínicas que oportunamente entraremos a clasificar y a detallar.

La mayor afluencia de enfermos se observó durante el brote epidémico presentado en el país en la Primavera de 1949 y en el Verano de 1950 . Felizmente, hasta la fecha, esta enfermedad no ha vuelto a hacerse presente con los caracteres epidémicos anotados en esa época, y desde entonces solamente hemos tenido pequeñas agrupaciones de casos que han reaparecido, coincidiendo en general con las épocas calurosas del año.

Para poner algún orden en las diversas formas en que la poliomielitis se manifiesta, especialmente durante estos brotes epidémicos, hemos procedido a clasificarlos de acuerdo con su sintomatología clínica y es así cómo hemos encontrado dos grandes modalidades:

I) De forma no paralitica, $y$

II) De forma paralítica y ésta con:

1) Sintomatología espinal;

2) Sintomatología encefálica, y

3) Sintomatologia mixta (encéfalo espinal).

La primera modalidad ha comprendido un escaso número de enfermos y sólo es posible investigarlos y comprobarlos en los periodos epidémicos. Por su sintomatología es lógico que no hayan sido hospitalizados, acudiendo sólo a la consulta externa o a la consulta privada del médico, en donde se ha diagnosticado un estado gripal; sin embargo, el diagnóstico definitivo sólo ha sido logrado por la presencia de otros casos en la familia, en la escuela, etc. y porque muchas veces algunos han presentado signos directos de irritación meníngea (vómitos fáciles, cefaleas, rigideces, dalores musculares generalizados), signos que son fugaces, o bien, porque en su convalecencia han presentado alguna manifestación de una paresia muy discreta.

La segunda modalidad es la que verdaderamente constituye la expresión máxima de la enfermedad, impropiamente llamada parálisis infantil, y es en ella la forma espinal la que alcanza el más alto porcentaje de frecuencia, ya que las formas encefálicas y mixtas sólo han Ilegado a totalizar en nuestra investigación 38 enfermos, que en relación con la cifra global de 220 enfermos sólo representa el $17 \%$. Por otra parte, hay que hacer presente que estas dos últimas formas sólo se observan durante los brotes epidémicos y en manera muy aislada, en los períodos de endemia.

Es a estos dos últimos grupos a los cuales nos referiremos especialmente en la presente comunicación, dejando para una próxima oportunidad los detalles de las poliomielitis espinales, como también los errores de diagnóstico cometidos en algunos enfermos que ingresaron como afectados de poliomielitis y en los cuales su evolución y un mayor estudio revelaron una diversa etiología; este error es muy explicable, ya que todos estos 
cuadros presentaban impotencias musculares y era lógico suponerlas originadas por el virus poliomielítico, ya que entonces nos encontrábamos en un franco período de epidemia.

Tampoco fué ésta la única dificultad con que tropezamos, ya que la falta de material casuistico solamente nos habia proporcionado conocimientos teóricos de las formas encefálicas; esta circunstancia se nos hizo aún más evidente al enfrentarnos a los tratamientos que en muchas ocasiones los hicimos erradamente, por no estar lo suficientemente adiestrados en el diagnóstico de las variedades y complicaciones a que da lugar la poliomielitis.

El grupo que trataremos más en detalle se refiere, como dijimos anteriormente, a aquél en el cual encontramos participación del encéfalo, sea ésta en forma más apreciable, 0 bien, en franca combinación con la lesión espinal. Desde luego, hacemos presente que es extraordinariamente raro encontrar un caso de poliomielitis que sólo presente síntomas encefálicos, sin que sea evidenciable algún compromiso de la médula espinal. En efecto, en un momento dado de su evolución, el virus de la poliomielitis ha invadido en forma difusa el sistema nervioso central, dando una sintomatología muy variada y de acuerdo con este compromiso general, pero que en los días siguientes se localiza en alguna parte de los núcleos bulbo protuberanciales, en donde lo hace de preferencia, o en los núcleos de origen de los nervios craneanos más altos.

De acuerdo con ia sintomatología predominante estos cuadros pueden agruparse, aunque en forma térica y para mayor claridad:

1) De forma difusa, que tomaría todo el encéfalo (polioencefalitis).

2) De formas localizadas:

A) Que comprende los núcleos craneanos por encima del octavo par, y

B) Que comprende los núcleos craneanos desde el noveno par hacia abajo y en que se incluyen, además, centros vitales íntimamente ligados en su anatomía y fisiología, como son:

a) El centro respiratorio, y

b) El centro circulatorio.

C) Que comprende núcleos encefálicos y espinales (formas mixtas).

Esta sistematización, aunque teórica, es muy útil para darnos cuenta de la manera cómo evoluciona la enfermedad y nos da únicamente una orientación sobre el momento en que efectuamos el examen del enfermo, pues la práctica nos ha enseñado que un paciente que en el primer examen hemos incluído en la clasificación " $A$ ", ese mismo día, o al día siguiente, cambia su sintomatología y evoluciona hasta encuadrarse en la categoria " $B$ ", como también en la categoría " $C$ ", o bien, recorre en diversos sentidos estas categorías sintomatológicas.

Como vemos, la poliomielitis es una afección eminentemente cambiante y sumamente difusa; por lo tanto, requiere una vigiláncia médica permanente, de manera que en todo momento podamos actuar con efectividad sobre el compromiso de los órganos que ella va atacando.

Las formas más frecuentes, aparte de las espinales puras, son las encéfalo espinales, y en ellas estarán comprendidas la mayoria de las anotaciones de que haremos comentario.

\section{Sintomatología.}

Los síntomas clínicos podemos clasificarlos en:

a) Síntomas de carácter general, y

b) Sintomas de carácter especifico.

I) Formas no paralíticas.

a) Sintomas generales:

Consisten en pequeñas alzas febriles, malestar general, que dura 2 ó 3 días y durante los cuales solamente se aprecia una debilidad muscular, razón por la cual los enfermos se resisten a cualquiera actividad. Esto pasa, sin dejar, por lo general, ninguna secuela. EI diagnóstico suele comprobarse con el examen del líquido céfalo-raquídeo, que puede demos- 
trar una ligera albuminosis y un pequeño aumento de los elementos.

b) Síntomas específicos:

Sólo se observan paresias, debilidad muscular pasajera, pero en general, puede decirse que hay ausencia de estos caracteres.

\section{II) Formas paralíticas.}

a) Signos generales:

Todas se manifiestan en forma parecida y es así cómo en el período prodrómico, que corresponde a la primera joroba de la curva de la temperatura llamada en "camello", encontramos fiebre, vómitos, catarro de las vías respiratorias altas, decaimiento, cefaleas, estados nauseosos, a veces diarrea, otras veces constipación. Este período dura de 1 a 4 días y es catalogado como una afección gripal corriente. EI período prodómico es seguido de un período de latencia, libre de síntomas, que puede durar de 1 a 10 días. Generalmente a los 3 aparece una nueva alza de la temperatura, la segunda joroba del camello, y se evidencian los síntomas que indican el compromiso del sistema nervioso central y que constituye la fase realmente especifica de la enfermedad. Los síntomas más frecuentemente encontrados, aparte de la fiebre, son los dolores generalizados, rigideces, sudoraciones, irritabilidad y negativismo, alteraciones de Ios reflejos en ausencia de parálisis establecidas y en algunos casos temblores y crisis convulsivas.

Las alteraciones del líquido céfalo-raquídeo, que aparecerian desde los primeros momentos de la invasión del sistema nervioso central, faltaron en un apreciable número de nuestros enfermos.

Las parálisis que dependen del compromiso espinal en general se presentan entre el segundo y el cuarto día de la fase específica de la enfermedad. En cambio, los síntomas que se originan en las lesiones del bulbo raquídeo tienden a aparecer más tardíamente, por lo general entre el cuarto y el sexto día de la enfermedad. Sin embargo, cuando los síntomas encefálicos son predominantes, ellos suelen hacerse presente desde el comienzo de la afección (principalmente la hipertermia).

Finalmente, hay que dejar constancia que en muchas ocasiones los síntomas prodrómicos son tan discretos que no alcanzan a ser apreciados.

b) Signos específicos:

Formas espinales: Durante el período febril aparecen las parálisis que han sido precedidas, por lo general, por dolores en las masas musculares. Estas parálisis son polimorfas; tan pronto se inician por los miembros inferiores y siguen una marcha ascendente, como pueden aparecer únicamente en un grupo muscular de un miembro determinado. La característica es que aparecen con una sintomatología muy alarmante, semejando un incendio de grandes llamaradas, que después se apaga, quedando afectados escasos grupos musculares, si se les compara con el número comprometido en su ruidosa iniciación. A veces las formas espinales se acompañan del compromiso de los músculos de la respiración (diafragma, intercostales), cuadro al que se agrega la anoxia y para el cual tiene el pulmotor una indicación precisa.

Formas encefálicas y encéfalos espinales.

Se comprende que la sintomatologia varíe según sea el grupo que describamos:

1) Formas difusas (polioencefalitis).

Este cornpromiso se presenta ya desde los primeros días y se traduce por aprehensión, irritabilidad, intranquilidad $\mathrm{y}$ espanto, a lo que se agregan espasmos musculares de la cara, la cual se presenta de un aspecto rojo, y temblor en las manos; el sueño es intranquilo por la excitación psicomotora. Sobreviene el confusionismo, la letargia, el período de somnolencia, el estado comatoso, y finalmente, la muerte del enfermo. Los signos cerebrales muchas veces suelen desaparecer, o atenuarse, si se combate la anoxia, asegurando una buena oxigenación. Esto inclinaría a pensar que en 
esas condiciones tal sintomatologia fuera debida más bien a la hipoxia y no a un daño cerebral ocasionado por el virus.

2) Formas localizadas.

A) Que comprende los núcleos craneanos por encima del octavo par: su sintomatología evidencia una lesión de los núcleos motores de los nervios craneanos y ellos son el tercero, el quinto, el sexto, el séptimo y el octavo pares y se traduce por ptosis palpebral, midriasis, estrabismo, diplopia, parálisis masticadora, asimetría de la cara.

B) Que comprende los núcleos craneanos desde el noveno par hacia abajo, incluyendo, además, el centro respiratorio $y$ el centro circulatorio.

a) Nervios inferiores:

Los núcleos más afectados son el del noveno, décimo y décimo primero pares, pero también suele comprometerse el duodécimo. De aqui su sintomatología: debilidad o parálisis del velo del paladar, de los músculos faríngeos y de las cuerdas vocales. Su iniciación se manifiesta por voz nasal, Jlanto débil, a veces afonia, otras veces ronquera; disfagia y acumulación de saliva en las cavidades bucal y faríngea. Esta sintomatología será aún más intensa si la lesión es bilateral. La falta de pasaje del aire por la laringe puede llevar al enfermo a una hipoxia, que se traduce por intranquilidad, aprehensión y aumento del esfuerzo respiratorio y esfuerzo cardíaco. La dificultad del pasaje del aire por la laringe se conoce por el estridor laringeo y disfonía, la disnea existente, a pesar de la buena excursión torácica, Ia cianosis y la aparición de signos de encefalitis.

b) Centro respiratorio:

Este centro está ubicado difusamente en la formación reticular del bulbo raquídeo. Su compromiso se manifiesta algunos dias después de haberse tomado los nervios craneanos. El ritmo y la profundidad de la respiración son irregulares, a pesar de haber una buena activi- dad del díafragma y de los músculos intercostales. Después la respiración se hace más superficial y los períodos de apnea son más largos. Eista se va haciendo cada vez más frecuente y más prolongada; suele aparecer el tipo de respiración de Cheyne-Stokes; hay aumento de la frecuencia del pulso y subida y mantenimiento de la fiebre. La presión arterial puede subir, o bien bajar, ocasionando un estado de shock. El enfermo está angustiado, aprehensivo y confuso, pero estos signos no son exclusivos, sino que también pueden ser debidos a la hipoxia. Después aparece la taquicardia, el descenso de la presión, la hipertermia, la cianosis $\mathrm{y}$, finalmente, sobreviene el deceso.

\section{c) Centro circulatorio:}

Su ubicación es la región mediana $y$ ventral de la formación reticular del bulbo raquídeo.

Su compromiso se presenta en los casos graves de poliomielitis bulbar, coexistiendo con alteraciones del centro respiratorio y con la de algunos nervios craneanos, cuya participación puede faltar, o bien, ser muy discreta. Se manifiesta por la apariencia de la cara, que está de color rojo oscuro como florecida. E1 pulso está muy alto, llega a 150 ó más, es de carácter irregular, a veces impalpable; la presión generalmente está baja, pero puede también estar elevada. La plel se presenta fría, húmeda y con cianosis. Después viene la hipertermia; la respiración se hace muy superficial, el enfermo está intranquilo, con ansiedad, aprehensión y confusionismo. EI fallecimiento suele venir en forma brusca. En los cortes del bulbo se han observado necrosis inflamatorias de la sustancia reticular medio ventral.

C) Que comprende núcleos craneanos y núcleos espinales. En estos casos la sintomatología demuestra tanto el compromiso espinal como el encefálico y su predominio puede ser tanto de parte de la médula como del encéfalo, dando lugar a una diversidad de modalidades clínicas. 


\section{La hipoxia en la poliomielitis bulbar.}

Antes que todo conviene dejar establecido que únicamente por comodidad se denominan procesos bulbares todos los procesos que atacan el encéfalo. Una de sus manifestaciones más importantes es la hipoxia, o sea, la falta relativa de la cantidad de oxígeno que reciben los tejidos por diferentes causas, que pueden ser:

a) Falta de oxigenación de la sangre en los pulmones;

b) Descenso de la capacidad de oxígeno en la sangre.

e) Disminución de la circulación sanguínea a través de los capilares.

Bancroft clasifica estos procesos anóxicos en las siguientes categorías:

Anoxia anóxica.

Anoxia anémica.

Anoxia por estagnación.

Anoxia histotónica, esta última causada por venenos que derivan de los procesos oxidativos de los tejidos.

El término anoxemia significa baja de la tensión del oxígeno en la sangre arterial y la asfixia es aquella variedad en que hay anoxia combinada con aumento de la tensión del $\mathrm{CO}^{\prime 2}$ en la sangre y en los tejidos.

La intensidad de la acción de este descenso de la tensión del oxígeno en la sangre se debe:

$1^{9}$ a la brusquedad de sll comienzo; $2^{\circ}$ al grado de la falta de oxigeno; $3^{\circ}$ a su duración, y $4^{\circ}$ a las condiciones generales del organismo.

En la poliomielitis encontramos el tipo anóxico, con disnea, cianosis, excitación, delirio, etc. y que depende de los factores antedichos.

Este tipo anóxico se debe a la baja de la tensión del aire inspirado (altura, aire confinado), o bien, cuando hay corto circuito venoso arterial en el corazón y especialmente en todas Las actividades que atañen al mecanismo pulmonar (neumonías, atelectasias, obstrucción y parálisis respiratorias). Este último aspecto es lo que nos interesa en la poliomielitis.
La hipoxia no sólo se presenta en la poliomielitis bulbar, sino que también to hace en las formas espinales que toman el diafragma, músculos intercostales y de la prensa abdominal, etc., de modo que la diferenciación entre estos 2 mecanismos, lesión de los centros bulbares y lesión de los centros espinales es muy importante por su pronóstico y tratamiento. También la hipoxia puede ser debida a que los enfermos presenten, además, una infección pulmonar sobreagregada (bronconeumonías, bronquitis, etc.). Esta complicación pulmonar es frecuente cuando falla la mecánica respiratoria, tanto en la lesión espinal como en la lesión bulbar y contribuye a aumentar la falta de oxígeno.

En las poliomielitis espinales sin compromiso de los músculos respiratorios es rara la complicación pulmonar en su iniciación, pero no así en su evolución posterior, sobre todo si se trata de lactantes en los cuales por su distrofia, la persistencia de la posición horizontal, etc., es fácil que se sobre-agreguen procesos pulmonares agudos. Esta complicación pulmonar tardía la observamos en muchos niños con secuelas dejadas por la poliomielitis y que se traducían en deformaciones torácicas, paresias o parálisis diafragmáticas.

En la poliomielitis bulbar la hipoxia resulta por diferentes mecanismos, cuyas causas están en las lesiones producidas en la sustancia gris bulbar y se pueden sistematizar en la siguiente forma:

19) Compromiso de los núcleọs motores del noverno y décimo pares, lo que acarrea los siguientes efectos:

a) Acumulación de secreciones en la cavidad bucal por parálisis muscular de los órganos de la deglución;

b) Parálisis de la lengua;

c) Obstrucción de la vía aérea por laringo espasmo reflejo;

d) Obstrucción de la vía aérea por parálisis de los abductores de las cuerdas vocales;

e) Acumulación de las secreciones por incapacidad para toser, $y$

f) Aspiración del vómito. 


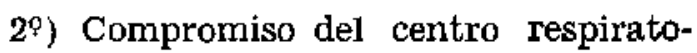
rio, que se manifiesta en:

lar, y

a) Respiración insuficiente e irregu-

b) Períodos de apnea.

$\left.3^{9}\right)$ Compromiso del centro circulatorio, que se traduce en:

a) Falla vasomotora.

$4^{9}$ ) Compromiso bulbar y cervical, con:

a) Alteración de los musculos principales y accesorios de la respiración.

$5^{\circ}$ ) Alteraciones en los pulmones, que pueden ser:

a) Edema pulmonar;

b) Atelectasia, y

c) Neumonías.

Cualquiera de las causas enunciadas, sea en forma aislada o combinada, ocasiona trastornos en la oxigenación, que se exterioriza clinicamente:

1er. estado: intranquilidad, aprehensión, ansieđad, insomnio.

$2^{\circ}$ estado: apariencia florida de la cara, aumento del número de pulsaciones, euforia, esfuerzo respiratorio, disminución del número de palabras pronunciadas en una respiración.

3er. estado: disnea, cianosis, alza febril, confusión y en ocasiones reacción de pánico.

$4^{9}$ estado: cianosis, fibrilación muscular, negativismo para responder a las preguntas, delirio, estado comatoso, shock terminal.

\section{Evolución y pronóstico.}

De 10 expuesto se deduce que no siendo la poliomielitis una entidad clínica unitaria, sobre todo si consideramos las variedades de la poliomielitis bulbar, su evolución dependerá entonces de la localización que afecten las lesiones.

En cuanto al pronóstico hay que considerario desde dos aspectos:

19) Con respecto a la vida del enfermo, $\mathrm{y}$

$\left.2^{\circ}\right)$ Con respecto a las lesiones paralíticas definitivas, o sea, las secuelas.

Como ya se ha dicho anteriormente, en los períodos endémicos la poliomieli- tis raras veces ataca a los centros bulbares, pero, en cambio, en las epidemias las formas altas son mas frecuentes, y por consiguiente, también es mayor la mortalidad.

La poliomielitis es grave en cuanto se refiere a la vida del entermo por las complicaciones respiratorias y circulatorias que produce y es asi cómo ellas tienen su maximo de frecuencia y de intensidad en las formas bulbares, por el compromiso del centro respiratorio o de los centros correspondientes a los músculos faríngeos y larıngeos, parálisis de los cuales ocasiona un ploqueo de las vias respiratorias.

Las parálisis de los músculos de la faringe en general suelen ser temporales y si los enfermos se defienden durante 4 a 6 días, sea por medio de la oxigenoterapia, la aspiración de las secreciones y la alimentación parenteral puede estimarse que el enfermo lentamente volverá a la normalidad.

También se ha observado compromiso del centro respiratorio en las parálisis espinales altas, en que existe lesión del diafragma, de los intercostales y abdominales.

La participación de los nervios craneanos superiores no tiene mayor importancia vital y hemos observado que estas parálisis son pasajeras. En cambio, la lesión de los núcleos de los nervios inferiores puede afectar la vida de los pacientes por ocasionar una obstrucción de las vias aéreas con una asfixia secundaria.

Con respecto a las secuelas, el pronóstico dependerá de los músculos afectados, siendo sombrío el porvenir de los enfermos con parálisis diafragamáticas y de los otros músculos respiratorios, ya que se encuentran expuestos con mayor facilidad al desarrollo de infecciones del aparato respiratorio.

\section{Tratamiento.}

El tratamiento etiológico anti-infeccioso es nulo; la poliomielitis no reacciona al suero de convalecientes ni a ninguno de los antibióticos actualmente co- 
nocidos. Sin embargo, dada la diversidad de sus manifestaciones, es lógico también la existencia de una variedad de tratamiento, pero de carácter sintomático, que tienden a eliminar las causas mecánicas que interfieren con los procesos vitales y que son las determinantes de la muerte.

Se ha tratado también de influir sobre el proceso de la poliomielitis por la deshidratación o por la sobre hidratación del sistema nervioso central, pero sin resultados efectivos.

Por lo tanto, en las formas bulbares la terapéutica estará orientada principalmente a corregir los síntomas predominantes.

a) Dificultad respiratoria: El oxígeno tiene un alto valor terapéutico en cualquiera falla de la respiración, pero sólo corrige una de sus fases: la necesidad de oxígeno, no mejorando la excreción de anhidrido carbónico. La terapia de oxígeno puede hacerse en tiendas especiales, como también por la inhalación directa, mediante variados dispositivos que se colocan en las fosas nasales. La experiencia nos ha demostrado la ventaja de asociar al oxígeno la inhalación de $\mathrm{CO}^{2}$ en una proporción de 4 a $6 \%$ del total de la mezcla.

b) Parálisis de los músculos faringeos y laríngeos: La parálisis de los músculos laríngeos acompaña a los de la musculatura faringea; no la hemos visto aisiadamente, salvo en un lactante de 1 mes, y su diagnóstico se hace muy difícil, porque la exploración directa de la laringe en estos casos es casi imposible y por demás peligrosa. Se la sospecha por la intensa dificultad respiratoria y por las alteraciones de la calidad de la voz $y$ del llanto. Su intensidad puede constituir una indicación formal de la traqueotomía.

La parálisis faríngea se manifiesta por la faita de deglución, acumulación de saliva y de secreciones, persistencia en la boca de los alimentos vomitados, circunstancias éstas que afectan el correcto pasaje del aire al sistema pulmonar y a corregir estos inconvenientes es a lo que debe estar orientada nuestra terapéutica mediante:

El drenaje postural;

La aspiracion de las secreciones faringeas, $y$

La iraqueotomía en caso necesario.

Para que el drenaje postural sea efectivo, la cabeza del enfermo debe ser colocada un pie más bajo que las extremidades; un gran alivio de esta posición se le produce al girar la cabeza hacia uno de los lados.

En la aspiración, la succión debe ser gentil y suficiente, pero en ningún caso exagerado, a fin de evitar los traumatismos de la mucosa. A veces con estas maniobras el paciente suele excitarse como también puede presentar náuseas.

Finalmente, disponemos de la traqueotomía, que si bien es cierto que tiene sus inconvenientes, como son la infección y el neumotórax, no debe ser pospuesta como último recurso, sino que debe ser practicada antes de que se presenten la cianosis y los ataques graves de asfixia. Su indicación depende de la efectividad de los resultados del drenaje postural y de la aspiración. En la parálisis de los múscuios faríngeos el enfermo debe calcular cada respiración, lo que lo lleva a la fatiga y luego a la inconsciencia: de aquí la necesidad de una oportuna traqueotomía.

c) Administración de líquidos: La parálisis de los músculos faríngeos hace que no sea conveniente dar líquidos ni sólidos por la boca. Debe procurarse una buena hidratación, dando agua, azúcar y sal, por vía rectal o endovenosa, sobre todo en los pacientes con intensas traspiraciones. El empleo de Ias sondas estomacales es peligroso, pues fácilmente se producen vómitos y sólo es aconsejable si el enfermo está afebril, con hambre y después que ha pasado el estado agudo de la enfermedad. Tampoco debe exagerarse la administración de líquidos, pues una sobrehidratación ocasiona un edema cerebral, como también edemas de la piel.

d) Sedación: La sedación se obtiene principalmente con la oxigenoterapia y si esto no se consigue, a pesar del drena- 
je y de la aspiración, debe procederse a la traqueotomia.

No es aconsejable el uso de los barbitúricos y de los opiáceos.

\section{Conclusiones,}

19) La poliomielitis se ha hecho presente en nuestro medio en estos últimos años y ha aparecido en forma de epidemia en sus épocas calurosas.

$2^{9}$ ) En estos brotes epidémicos se han observado las formas bulbares en un porcentaje que llega al $17 \%$

$3^{\circ}$ ) Estas formas son las que, a su vez, han alcanzado el más aito coeficiente de mortalidad por los trastornos respiratorios y circulatorios: algunas de ellas han sido de una evolución fulminante. Los trastornos ocasionados por lesiones espinales son más benignos y son los que han cedido al tratamiento adecuado.

$4^{\circ}$ ) En el tratamiento de las alteraciones respiratorias de las poliomielitis espinales el empleo del pulmotor es de una evidente eficacia inmediata. Su pronóstico queda supeditado a la posibilidad de secuelas de los músculos respiratorios, que favorecerán las complicaciones infecciosas pulmonares.

$\left.5^{9}\right)$ Para el tratamiento de la poliomielitis bulbar se requiere un equipo de médicos y de enfermeras que tengan hábito en la observación y atención de estos enfermos, y además, de una instalación mecánica de aspiración, de oxige- nación, de administración de anhidrido carbónico, de alimentos por vía parenteral, como también de dispositivos para cambiar con facilidad la posición de los enfermos.

\section{Summary.}

1) Poliomelytis has appeared among us these last years in an epidemic form during the warm seasons.

2) In these epidemic outbursts bulbar type poliomeiytis has accounted for $17 \%$ of the cases.

3) These forms have accounted for the highest mortality rate due to the respirarory and circulatory complications; in some cases the evolution has been rapidiy fatal. The complication caused by spinal localization are more benign and are those that have responded to adequate treatment.

4) In the treatment of the respiratory complications of spinal poliomelytis the iron lung is of an evident immediat benefit. Its prognosis would be conditioned by the possibility of sequela of the respiratory muscles that will favor pulmonary complications.

5) In the treatment of the bulbar type a team of specially trained doctors and nurses is esential as well as a complete set of appliances for aspiration, oxigenation, administration of carbonic hydrate, parentheral feeding as well as changes in the position of the patients. 